\title{
La melancolía, una pasión inútil
}

RESUMEN: En el presente artículo se analiza si existe una utilidad subjetiva del síntoma melancólico y qué tipo de expresiones, psicopatológicas o no, se pueden derivar de él.

PALABRAS CLAVE: Depresión, genio, melancolía.
SUMMARY: This article analyzes if there is an usefulness of melancholic symptom and which kind of expressions, either psychopatological or not, can come from it.

KEY WORDS: Depression, genius, melancholy.

\section{Justificación}

\section{Sombras}

La melancolía es, al menos, un problema clínico, nosográfico, histórico, filosófico, artístico y cultural, si es que cabe la separación entre estos diversos frentes. Su historia es la de la psiquiatría misma, y su estudio, el del dolor que acarrea la propia condición humana. Desde una perspectiva como ésta no extrañarán las dificultades que han acompañado siempre a cuantos han enfrentado la tarea ya de su descripción, ya de su explicación desde las ciencias de la naturaleza o del espíritu. Se atenderá aquí, entonces, más a sus ambigüedades que a los logros obtenidos en su conocimiento, y acaso no será un error considerar la zozobra que envuelve estas páginas un efecto más de la cualidad turbadora, escurridiza y límite de la melancolía, de su capacidad para confundir y subvertir, cuando no de aterrar, en el sentido de un horror atávico y cerval, tanto como en el de un echar por tierra cualquier tentativa de acercarse a sus misterios.

La sombra de la melancolía cae así sobre sí misma, haciendo que el objeto de nuestro estudio se desvanezca ante nuestros ojos, perdido en una inquietante penumbra semántica y filosófica, antes incluso que nosográfica. Hay una tristeza del pueblo y una tristeza de los filósofos, y dentro aún de ésta, una tristeza como ametría, como desviación del término medio, y otra consustancial al hombre de genio. Hay una melancolía que es sinónimo vago de locura y toda una serie de intentos de cernirla: de Areteo de Capadocia a J. P. Falret, de Hipócrates a la neurofisiología.

No tarda en aparecer ante nosotros una segunda sombra: la de la propia melancolía abatiéndose sobre cualquier teoría del sujeto. Toda indagación en este sentido habría de vérselas en primera instancia con un sujeto natural, que para Hipócrates es espejo del macrocosmos, cuya pesadumbre es fruto de la discrasia humoral y por cuyas venas fluye una sangre enturbiada por efecto de la atrabilis. 
Pero también debería lidiar con un sujeto moral, con un sujeto del conocimiento -antes y después de Descartes-. Y plantear, en cada caso, los interrogantes a que aboca la experiencia melancólica, que se adivina ya, tras sus muy diversas máscaras, como una pasión universal.

\section{Luces}

Aunque no sea nuestra intención abordar una polémica que se dilata por siglos, nos enfrentamos a la tarea inexcusable de definir nuestro objeto de estudio. Un esquema general podría ser el siguiente: cuanto aquí se diga de la melancolía apuntará, por un lado, a una disposición psíquica especial, que se ha querido hermana del arte y de la locura, y que entenderemos en su sentido más extendido de tristeza profunda. Por otro lado, tendrá que ver con el vasto espectro de lo depresivo, con la melancolía entendida como crisis, experiencia que utilizaremos a modo de palmatoria para conducirnos por las sombras de sus relaciones con el deseo y la psicosis, lugar este último donde quizá con excesiva valentía se la sitúa con frecuencia.

Partiremos para ello de una concepción positiva del síntoma, del convencimiento de que éste lleva a cabo una función que emanará precisamente de un compromiso y un trabajo subjetivos. Con la vista puesta en la utilidad para el sujeto, dudaremos que exista efectivamente esta tarea en la melancolía, aun dejando abierta la posibilidad de contradecirnos una y mil veces, comenzando por el título mismo de nuestra propuesta: lo inútil que aquel trabajo pueda resultar. La paradoja, llevada al extremo, nos mostrará al melancólico, al inútil, como la potencia de toda creación, sintomática, artística y cultural. Llegado ese punto, hablaremos de genio y revolución y, caída sobre nosotros la sombra de nuestro objeto de estudio, acabaremos por llevarnos de nuevo la contraria y sumirnos en una apenas remozada oscuridad.

\section{Ausencias}

Que se defienda una causalidad psíquica de la melancolía no supondrá necesariamente desdeñar lo que las investigaciones biológicas en psiquiatría han sugerido en numerosos estudios. Si el psicoanálisis pretende, desde las aportaciones de Freud y Abraham, hermanar la experiencia de la tristeza con aquella universal que supone la pérdida, el duelo en su sentido más amplio, nada nos impide a nosotros suponer al melancólico singularmente ávido, con Aristóteles, que afirma en el 
célebre Problema XXX que los melancólicos son, en su mayor parte, lujuriosos (5). El mismo Abraham se vio abocado a postular una «intensificación constitucional del erotismo oral» como condición para el acontecimiento depresivo (1). Los criterios DSM-IV para añadir a una depresión el apellido de melancólica son referencias a lo somático como sede última del conflicto de la tristeza, perturbaciones de las necesidades vitales como el sueño o la nutrición (4). El cuerpo puede ser, por qué no, escenario del estallido melancólico, del fragor de su lucha y efectos y de algunas de sus posibles salidas, como las llamaremos más adelante. Por nuestra parte, justificaremos que no se hable aquí del litio ni de la neurotransmisión llanamente porque no nos es necesario. Baste con recordar que la fisiología nos ha descrito un sistema neuroendocrino rítmico, cíclico, un hipotálamo como productor pulsátil e incesante de hambres y necesidades. Al igual que el yo neurótico que, como «función de desconocimiento» crea sus propios señuelos y pruritos de satisfacción e incita a una búsqueda durante la cual el deseo corre el riesgo de desfallecer, el cuerpo biológico es un prodigioso señalador de faltas y generador de avideces, de posibilidades de patentizar la pérdida por la ausencia. Hambre, sed o celo, no son más que señales fisiológicas de la incompletud y la dependencia, y podrán precipitar, por la misma vía, la crisis melancólica.

\section{El dolor y sus bálsamos}

Tristezas...

Existe siempre la posibilidad de la tristeza. Como un ocaso del impulso vital, como un automatismo lacrimoso presto siempre a afectar al hombre, ya sea porque algo se haya perdido, ya porque del horizonte se borre la promesa de su consecución. Hay tristezas que se quieren del cuerpo y otras que implican al alma. Hay el duelo y sus complicaciones. Hay depresiones neuróticas, liminares y psicóticas, e incluso las hay postpsicóticas e inducidas por neurolépticos. Se habla de la herencia de la depresión y, más aún, de una tristeza que es enfermedad, que tiene una etiología, y que cura con los nuevos eléboros que proliferan en la vereda de la práctica psiquiátrica.

Durante siglos, la experiencia de una tristeza profunda se mostró hasta tal punto natural al observador, tan surgida de la entraña misma de lo humano, que su propio nombre bastó para explicar su origen. Melancólico era, ni más ni menos, aquél en quien predominaba la melanos cholés, uno de los cuatro humores fundamentales que animaban el cuerpo. La misma bilis negra, húmeda, pesada y fría determinaba un cuadro que, en lo afectivo, compartía con ella sus cualidades. 
Llegado el siglo XIX, la ciencia psiquiátrica se enfrenta a la tarea de sistematizar las especies de una alienación por el momento unitaria. La melancolía comienza entonces a esconderse, a escapar de un intento de clasificación. Se trata, para Pinel, de la primera especie de esta locura única (33), y Esquirol, poco más tarde, intentará hacerla definitivamente patrimonio de la ciencia médica con la difusión de un término que no acabó de resultar exitoso, el de lipemanía. Tentativa que sí cuajará en la obra de Falret padre, cuya folie circulaire sirve de inmejorable acomodo para la adopción del método anatomoclínico por la psiquiatría $(3,23)$. Aunque se hablase ya de ciertas tristezas como enfermedades en sí mismas, las pasiones en general y la tristeza como pasión privilegiada seguirían siendo culpables de la producción de los más severos trastornos del juicio. El propio Falret es un ejemplo de este punto de vista, y para Griesinger son, de hecho y pese a su expreso organicismo, las responsables de la «puesta en marcha» de la psicosis (3). Y pese a que se caminaba hacia el horizonte de la lesión orgánica, los clínicos del XIX encontraron que algunas tristezas extremadas podían ser a un tiempo manifestación sintomática y origen de otros nuevos síntomas, anticipando la idea de una «adaptación» del sujeto a su malestar. De otro lado, las pequeñas depresiones neuróticas, duelos trabados de andar por casa, como hermanas pobres de una estrepitosa y manicomiable melancolía, podemos suponer que quedaban durante el siglo XIX en manos de internistas, sacerdotes, curanderos y familiares compasivos.

Si a la psiquiatría médica no le tiembla el pulso en segregar al que delira, o al ciclador que repite sin explicación un mismo vaivén, para una ciencia psicopatológica el dirimir sobre la melancolía plantea serias dudas, que atañen al borroso y muy polémico límite entre lo normal y lo patológico. Hasta tal punto parece una experiencia universal, que el mismo Jaspers debe incluirla dentro de lo comprensible, y al devenir del melancólico, dentro de los desarrollos de la personalidad (24). Nada parece más comprensible que la tristeza o la alegría, y sin embargo tenemos que aceptar cierto extremo de tales manifestaciones como un trastorno. Lo que asusta, entonces, de la melancolía es precisamente que sea una simple «exageración de la normalidad». Comprendemos la tristeza, la inapetencia, las cavilaciones constantes, el nerviosismo, pero nos asusta su desmesura: el estupor, la anorexia, el insomnio, la profunda angustia que acompaña al melancólico. Y, sobre todo, la soledad y el suicidio. Desde una concepción religiosa del orden natural, que suplanta a dios como dueño de la vida por la ley de la propia conservación, aterra pensar en un planteamiento vital que prescinda de las servidumbres de la carne. Lo deliroide, por comprensible, turba porque sugiere una amenaza siempre en ciernes, la posibilidad de que, en algún momento, uno pueda ser presa de tan inmenso sentimiento de desamparo. El sentido común, aterrado ante su propia caricatura, busca una explicación cualitativa para el maldito, para el condena- 
do. Así lo hace también la psiquiatría durante el siglo XIX: debe haber una disfunción o una lesión orgánica. Y, ya en el siglo XX, se busca una «perturbación generadora» que explique los inquietantes excesos de la tristeza (27). Freud se muestra también desconcertado ante las semejanzas entre duelo y melancolía, y estudiará en 1915 las condiciones en que se elige ese objeto cuyo duelo resulta a la postre imposible y deriva en manifestaciones clínicas tan dolorosas.

Podría parecer que la psiquiatría misma se defiende como puede de una melancolía siempre al acecho, y llegada estos días a ciertos extremos, de la posibilidad siquiera de una tristeza normal. Pero volvamos al siglo XIX, porque es dentro de la suposición de una alteración cerebral subyacente donde germina, en la obra de ciertos clínicos, la idea de que parte de las manifestaciones semiológicas de determinadas enfermedades es fruto del esfuerzo subjetivo por adaptarse al proceso patológico mismo.

... y trabajos.

Se puede decir que este punto de vista se inaugura, al tiempo que la propia ciencia psiquiátrica, con la obra de Pinel. Que su melancolía sea un delirio parcial, es una clara muestra del margen de humanidad inalienable que presuponía al alienado y que hacía posible su participación en un tratamiento moral $(2,3,23)$. Más aún, Pinel, que privilegia los trastornos del juicio en su concepto de alienación mental, incluye como una de sus especies la «manía sin delirio», abriendo, por un lado, la posibilidad de la medicalización de cualquier exceso, de cualquier desmán de lo cuantitativo, pero permitiendo, por otro, la participación de un sujeto responsable en su propio síntoma. Frente a esta idea, y especialmente frente a las herederas de aquella manía sin delirio que fueron las monomanías de Esquirol, se alzaría la voz del discurso más médico en la figura de J.P. Falret: no se concibe una alteración del juicio que no sea global, de lo que se sigue que el individuo nada tiene que ver con la génesis ni el desarrollo de su enfermedad mental (2).

Pese a todo, y ya dentro de una concepción eminentemente médica y somatizadora de las cuitas del alma, es a través de las sutiles y rigurosas descripciones de algunos clínicos como se devuelve al individuo cierta competencia en cuanto a las manifestaciones de su malestar. El semiólogo atento acaba por identificar lo que de cada cuadro sintomático produce el propio sujeto en su lucha con la enfermedad. En lo que respecta a la melancolía, una muestra ejemplar de este punto de vista es la obra de Jules Séglas.

Sirvan aquí de ilustración las aportaciones del psiquiatra francés en sus Leçons Cliniques de 1895. Intentando dilucidar el orden de aparición de los fenó- 
menos en la «melancolía sin delirio», Séglas aísla dos problemas fundamentales: por un lado, el estado emocional, profundamente doloroso; por otro, las dificultades en el ejercicio intelectual. Toda otra manifestación clínica es entendida por el francés como un producto secundario derivado de aquéllos. En un análisis ulterior, toma partido por una alteración cenestésica y una dificultad progresiva de lo ideomotriz como fenómenos anteriores al dolor moral, adscribiéndose así a una opinión a la que pertenece también, por ejemplo, Kraepelin (26). La tristeza es, en Séglas, secundaria a estos fenómenos de inhibición, y tiene su razón de ser en la singular conciencia de su déficit que cabe suponer al melancólico. Para el psiquiatra francés, el acontecimiento del delirio en este sustrato de abatimiento y dolor no significa sino una «tentativa de explicación». Si la melancolía simple se detiene aquí, a lo sumo preguntándose por su parte de culpa en el proceso, la melancolía delirante anticipa la respuesta. Siguiendo en ello a Griesinger, Séglas hace derivar el delirio melancólico del automatismo mental. En su búsqueda de una explicación, al melancólico esta respuesta se le aparece revelada, organizándose en torno a ella un delirio de características especiales: humillación, culpa, ruina... cuya apariencia estática es acorde con la inhibición de que proviene y con una específica vivencia del tiempo, mereciendo para Séglas el calificativo de «delirio de espera» (35).

Merece la pena que nos detengamos aquí por diversos motivos. El primero, para señalar que, habiendo tomado como modelo la melancolía para este recorrido, no hemos hallado aún a cuál de sus procesos podríamos llamar «trabajo útil». Nada nos hace suponer, hasta ahora, que el mecanismo del delirio, como ejemplo de laboriosidad subjetiva, le sea específico. Y sigue siendo una incógnita qué beneficio podemos asignar al trabajo del melancólico simple, que se limita a dolerse de su impotencia sin avanzar más respuesta que tímidas ideas de culpa. El segundo motivo de nuestro alto será una breve pero indispensable mención a las aportaciones de Sigmund Freud en torno a la utilidad de determinadas elaboraciones psíquicas.

Debemos al padre del psicoanálisis la posibilidad de explicar las psiconeurosis funcionales como efectos de una lucha interior. El conflicto, que es la madre de toda la psicopatología psicoanalítica, involucra al sujeto propuesto por Freud tanto en su producción como en las maniobras dedicadas a resolverlo. Más aún: privilegia a éste como su modo genuino de expresión. Visto como una formación de compromiso, se puede comprender que su función última sea la del restablecimiento de la salud alterada por el conflicto. Salvando la paradoja, si ya en su día la propuesta resultó revolucionaria en el campo de las neurosis, más aún lo sería en el de las psicosis. Cuando Freud publica su análisis del Caso Schreber, la idea que imperaba sobre el proceso psicótico era la de una evolución hacia el deterio- 
ro. Aún no había triunfado el término esquizofrenia, y la entidad nosográfica kraepeliniana de «demencia precoz» no sugería en absoluto la capacidad creativa que Freud otorga al supuesto demente. Calificar un sistema delirante de «tentativa de curación» devuelve, incluso al enfermo mental que se quiso más desposeído, no ya el protagonismo en su enfermedad sino la responsabilidad del primer y más genuino intento de restañar sus propias heridas.

Siguiendo esta línea de pensamiento, Bleuler inaugurará una psicopatología influida, merced a la relación de Freud con Jung y la clínica de Burghölzi, por ciertos elementos de inspiración psicoanalítica. Cuando el suizo establece el símil entre la osteomalacia y la esquizofrenia viene a plantear que, a partir de una perturbación esencial, lo que el sujeto lleva a cabo no es ya la mera búsqueda de una explicación, sino toda una serie de signos y síntomas secundarios que se derivan directamente de su esfuerzo por adaptarse al mundo, al prójimo y a su propia enfermedad. En idéntico sentido se pueden entender ciertas construcciones teóricas de grandes psicopatólogos del siglo XX, como Minkowski, Binswanger o Henri Ey (29). Hablando de la melancolía, una de las más célebres monografías de la segunda mitad del siglo XX, la que firma Tellenbach, supone un intento parecido.

Hemos hablado hasta aquí del dolor y del doliente, de una tristeza ubicua y un individuo en acción, concediéndole al sujeto el papel protagonista del que, no en vano, es su propio drama personal. Se trata ahora de esclarecer, desde el psicoanálisis, a qué razones responde ese dolor, por ver si arroja luz sobre su supuesta inutilidad.

\section{La herida y sus márgenes}

El mismo año en que se publicaban las referidas Leçons Cliniques de Séglas, Freud dejó escritas en su Manuscrito G ciertas consideraciones sobre la melancolía que pueden ser puestas en serie con las opiniones del psiquiatra francés. Si para éste la tristeza del melancólico se debe a la conciencia de su propia inhibición, para Freud «la mejor descripción» era la de una «inhibición psíquica con empobrecimiento pulsional, y dolor por ello» (21). Ya en las primeras líneas, Freud anticipaba además otra idea: «El afecto correspondiente a la melancolía es el del duelo, o sea, la añoranza de algo perdido» (22). De ello se ocupará, ya desde una perspectiva psicopatológica, en su célebre artículo de 1915, Duelo y melancolía. Se tratará, en ambos casos, de un trabajo, de una labor que permita superar el pesar por esa pérdida renunciando al objeto perdido. Un Freud especialmente optimista concederá al duelo la posibilidad de llevar a buen fin tal tarea (12), cuestionándo- 
se de qué manera puede esto suceder en la melancolía, toda vez que ha postulado para ella una identificación del yo al objeto (20).

Aparece ya ante nosotros una primera diferencia entre las propiedades curativas que pueden ser atribuidas a los otros trabajos que propone la nosografía freudiana y la que corresponde a la melancolía. Para la neurosis y la psicosis se trata de desear o delirar, de subsanar un conflicto fundamental con el empeño interminable del uno o del otro esfuerzo, sirviendo este mismo empeño, per se, de bálsamo. El melancólico, en cambio, sufre precisamente de ese trabajo: hay una identidad entre el padecer y un supuesto laborar por su propio restablecimiento. La condición para que este trabajo resulte finalmente útil es, paradójicamente, que concluya. Es aquí donde debemos situar la inutilidad a que se refiere el título de nuestro artículo, por cuanto la posibilidad de tal acontecimiento se nos aparece, igual que a Freud, como un misterio. Lo que aquí propondremos como salida a la crisis melancólica no significará el triunfo de su quehacer, sino la asunción de otro que ya no le será propio.

La misma sensación nos produce la lectura de los trabajos kleinianos sobre los estados maníaco-depresivos. Determinadas defensas acuden al auxilio del sujeto para ayudarlo a superar las ansiedades específicas de cada una de las posiciones que propuso la psicoanalista húngara. Pero ninguna parece emanar de la posición depresiva. Negación y omnipotencia son suturas provisionales hijas de un sustrato maníaco, y el mecanismo de la reparación echa ya raíces en lo obsesivo. Rozando lo pleonástico, lo único que Klein defiende como propio del trabajo melancólico es el penar, sugiriéndonos que el hombre, enfrentado a la herida abierta de su propia naturaleza, la acepta: se niega a defenderse de ser humano.

Y algo parecido nos sucede con la postura que adoptó Lacan frente al problema de la melancolía. Podemos, con él, considerar el deseo como el motor que anima al neurótico a buscar, aun sin posibilidades de éxito, el objeto que colme esa falla primordial. Y podemos ver en el delirio el remedo de aquel mecanismo, la prótesis discursiva de que se vale un psicótico que, por estructura, no ha accedido al mundo del deseo. Incluso la perversión cuenta con las armas de la escisión y la negación para satisfacerse sin mayores culpas. El melancólico, muy al contrario, carece de cualquiera de estos modos particulares del vivir. El desfallecimiento del deseo como discurso lo deja en una posición de renunciamiento, identificado al dolor (34). Esta inmovilidad, esta detención del pulso mismo de la vida, es la que lo aproxima a la muerte y al suicidio.

\section{Paciencias...}

Cuando Freud, empecinado en llevar a sus últimas consecuencias el paralelismo entre duelo y melancolía, se ve llamado a explicar por qué ésta, sobre todo 
en su presentación cíclica, tiene también un final, acaba, sumido en dudas, por ofrecer dos alternativas: o bien se renuncia al objeto, al que el doliente se ha identificado, o debemos aceptar que la cólera del yo tiene un límite, que todo fuego acaba por apagarse (20).

Parece, en ambos casos, que se trata de una cuestión de paciencia, de una «capacidad para padecer» tanto como de un agotarse ésta hasta el punto de tomar la salida más cercana. De estas salidas hablaremos a continuación, dejándonos atrapar por una paradoja que se nos aparece como insalvable. Hemos tratado, hasta ahora, de proponer el trabajo melancólico como una labor estéril, sin más resultado que la deriva hacia la muerte, cuando no la muerte en vida. Se trata ahora de contradecirnos y proponer un callejón sin salida colmado de grietas, de butrones, de puertas incluso. Aunque no sean específicas del melancólico, ante sus ojos se abren tan diversas posibilidades que hacen de su labor la inutilidad más fértil, la potencia casi de toda creación sintomática.

\section{...de la carne}

Puede entenderse el fin de cada fase de las clásicas psicosis circulares como Freud lo entendió: el Yo, en batalla contra sí mismo, agota sus fuerzas, comienza a jadear tras nueve meses de automartirio y abandona, por imposible, su tarea de escarmentador. Si no muere en la batalla, el melancólico, entregado a la estéril tarea de la mortificación, pierde su paciencia. Como un Sísifo que arrojase la piedra ladera abajo, se rebela y vuelve a una insulsa y discutible paz. O coquetea, en forma de manía, con un triunfo ilusorio y desesperado que tampoco acabará de satisfacerle. Nada nos impide, sin embargo, dar la razón al atrabiliario Cioran cuando afirma que «contrariamente a los placeres, los dolores no conducen a la saciedad» (11). Saturado el placer sádico de la ira o desfallecidas sus fuerzas, de aquella herida irrestañable surge de nuevo el incendio, para volver a apagarse acabada la fase. El castigo, por eterno, no ha de presentarse forzosamente como continuo. La repetición periódica del martirio puede entenderse como el eterno retorno nietzscheano: una forma de afirmación (15), de otorgar un peso a la propia opción de vida. Lo absurdo del denuedo melancólico en su propia e inútil mortificación no ha de empañar su valentía, puesta de manifiesto en el hecho de que está destinado a repetirla una y otra vez. Borges, analizando el problema de la eternidad del infierno, nos propone una lectura que casa muy bien con la condición de hombre excepcional que se ha atribuido al melancólico. Si los teólogos, con sutilezas escolásticas, intentaron zafarse de la posibilidad blasfema de que el castigo, por infinito, se equiparase a la gracia, el argentino defiende la paradoja de 
forma concisa: «Hay eternidad del infierno porque la dignidad del libre albedrío así lo precisa» (9). Aquél que ha nacido bajo la influencia de Saturno, de Cronos, sabe de la trascendencia de su pecado y acepta, responsable, una condena eterna, aun cuando se rebele de cuando en cuando, agotada su paciencia, no por mala fe sino por auténtica pasión humana.

De las opciones que Freud propone para el fin del trabajo melancólico, la del renunciamiento al sí mismo como objeto se nos antoja especialmente radical. El suicidio como salida da cuenta del fin de la paciencia de la carne y también de la del alma. Igual nos da que se abandone o se defenestre, o que se entregue al falso hedonismo de los equivalentes suicidas en la manía. Cuando para el melancólico desaparece ese último amarre que es la identidad con el dolor, y como expresión máxima de su rebeldía, se da muerte. Lo cual muchas veces coincide, como gesto postrero, precisamente con el momento en que concluye una de las fases, cuando se levanta la inhibición psicomotriz, algo que los clínicos avisados tienen siempre presente.

\section{... y del espíritu}

El melancólico puede, asimismo, cansarse de una guerra en la que vencer es llanamente imposible y tomar otros caminos que la mortificación. Ya Aristóteles había llamado la atención acerca de sus posibilidades expresivas: al equiparar las facultades de la atrabilis a las del vino, propone un melancólico capaz de desplegar todo el espectro de los caracteres del hombre. Lo que el vino propicia por el tiempo que duran sus efectos, lo posibilita la bilis negra de por vida (5). El atrabiliario da la razón a Aristóteles y muestra que sus salidas abarcan casi toda la psicopatología.

Puede, por ejemplo, retomar el camino de la neurosis. Sin aventurarnos a especular sobre el mecanismo que pone de nuevo en marcha la máquina deseante, nos bastará con atender a los ejemplos que durante siglo y medio avalan la existencia de melancolías que no pasan de uno o dos accesos y encuentran la paz en una suerte de normalidad de peculiares características, que incluyen cierta rigidez y gusto por la norma. Pareciera como si el melancólico encontrase en la proyección de la esencia humana que proponía Feuerbach un ideal pseudorreligioso más modesto y alcanzable, y que se entregase al cumplimiento de una ley, divina o mundana, como tabla de salvación. El parentesco entre la melancolía y las manifestaciones de la neurosis obsesiva ha sido señalado por el psicoanálisis en numerosas ocasiones. Bajo una apariencia de actividad incesante, el obsesivo no hace nada, se muestra igual de inútil. Entregados ambos más a preocupaciones que a 
una verdadera ocupación, dan cuenta de una misma vocación estática, como la que sugería aquél «delirio de espera» al que hacía mención Séglas. Fuera de esta corriente de pensamiento, autores poco sospechosos de veleidades psicoanalíticas han señalado también este parentesco. Kraepelin mismo, que aproxima la melancolía a la «locura de los degenerados» por sus «obsesiones» constantes (24). O Tellenbach, que en su célebre monografía proclama como nuclear en este síndrome endógeno el «afán de orden» (38). Una feliz coincidencia nos lleva incluso a Baudelaire, quien, seducido desde su llegada a París por los pulsos mortecinos de la atrabilis que destilaba el gigantesco bazo que era el siglo XIX, hace que, en sus Flores del mal, a las cuatro versiones del Spleen le sucedan significativamente la Obsesión y El gusto de la nada (6).

Harto del peso de la culpa, una inversión radical de las razones del universo puede llevar al melancólico a proclamarse tan inocente como el paranoico de cuantos crímenes él mismo se arrogó en el pasado. La melancolía, que se ha hermanado con la paranoia desde el nacimiento de la ciencia psiquiátrica, es situada por Pinel dentro de los delirios parciales, por Esquirol en el grupo de las monomanías, y aun por gran parte de los autores de los siglos XIX y XX no ya como entidad clínica susceptible de aparecer en comorbilidad con el delirio, sino como origen de uno de sus tipos, del que el descrito por Cotard es ejemplo paradigmático (14). Todavía en nuestros días se mantiene viva la llama de esta polémica por la necesaria persistencia de una categoría diagnóstica como el trastorno esquizoafectivo. Como quiera que sea, parece que, salvando estas disquisiciones psicopatológicas, la melancolía puede llamar en su auxilio al delirio como flujo discursivo que la saque de la inercia mortal de su crisis y postergue la muerte definitiva de manera asintótica, con la certeza megalomaníaca, por ejemplo, de una muerte en vida. $\mathrm{O}$ incluso más, que se rebele, como hemos dicho, ante su propio destino culpable y pase a acusar al prójimo de las más diversas conspiraciones, infamias $\mathrm{y}$ asedios.

Llevada la especulación a su extremo, y conscientes de este otro salto cualitativo, podríamos llegar a ver el coqueteo melancólico con la fragmentación y el automatismo como otra de sus posibilidades, a la que se llegaría, por ejemplo, a través de un estupor que rozase la catatonía o de una disociación extrema que llegase a emular la escisión esquizofrénica. Incluso podríamos considerar otras muy diversas patologías, que se pasean por el límite especulativo entre neurosis y psicosis, o que son hijas en cierta medida de la perversión, como defensas contra este dolor primordial. Herederas de algunas monomanías que terminaron por entenderse como locura moral (23), antes que precipitarse en la crisis, preferirían enzarzarse en las más desesperadas relaciones de amor y odio con el otro, cuando no salvar el abismo con la vehemencia del paso al acto. 


\section{Fe de paradojas}

\section{Melancolía, genio y subversión}

Hemos considerado hasta ahora la melancolía como crisis, como acontecimiento fatal en que el deseo fracasa en su función narrativa. Hemos visto, sin embargo, que de su identificación con el dolor, con el pathos, con la paciencia entendida como «capacidad para padecer», pueden surgir las más diversas creaciones sintomáticas que desdigan como potencia lo inútil que ella pueda ser en origen. Nos disponemos ahora a tratar de aquello que llamamos al principio disposición psíquica, análoga a la crisis, pero con otras consecuencias que la muerte o la psicopatología, esto es, la melancolía como fuente de la creación artística, y aun de alguna suerte de revolución.

De camino a lo que se nos aparece como una nueva y última contradicción, nos limitaremos a añadir a la ingente literatura sobre las relaciones entre melancolía y genio sólo unas pinceladas que nos la pinten como creadora y, llegado el caso, como destructora. En tanto disposición psíquica, el temple melancólico incluye la impaciencia, el afán de perfección que hace de ella condición casi sine qua non entre los «hombres excepcionales» y que podemos atribuir a esa vocación utopista por alcanzar el ideal. Si éste paraliza en la crisis, aquí sirve de acicate hacia la belleza. Aunque es consciente, con esa hiriente lucidez que le atribuyó Freud, de la cesura insalvable que lo separa de esa quimera, no por ello va a dejar el melancólico de aspirar a ese espejismo de perfección. Y ello porque se trata, ante todo, de una utopía subjetiva (37) destinada a conciliar una ambivalencia que le es consustancial. La poiesis melancólica surge de esa dialéctica, de una verdadera y primordial lucha intestina que tiene por meta el ideal, no por altruismo sino por necesidad. Considerada también como una salida, como otro agotarse de su paciencia, el destemplado melancólico puede lanzarse a crear para sanar su herida. Dejó dicho Burton que escribía para curarse del mal melancólico, y Baudelaire describió las servidumbres del «yo culpable del poeta» en su Spleen de París con las siguientes palabras: «El estudio de la belleza es un duelo en que el artista da gritos de terror antes de caer derrotado» (7).

Pero la melancolía conoce otras versiones del arte y la rebeldía que su vocación conciliadora. La manera de conducirse ante sí y ante el mundo nace de la «constelación anímica de la rebelión», dice Freud. Alienado al objeto ante todo por amor, utopista por naturaleza, es capaz de sublevarse contra falsos ideales y denunciarlos a martillazos, con toda la violencia de su cólera. Caído o difuminado el ideal colectivo, intentará sostenerlo porque para él se trata de una cuestión de vida o muerte, de algo que atañe a su propia identidad. La propuesta revolu- 
cionaria de los dadaístas, aquella que precedió al surrealismo y se disolvió en su propia anarquía, puede ser un ejemplo de ese arte destructor.

Hay aún otra utilidad de este fuego de la atrabilis: la que lo convierte, por su natural orgulloso, en una denuncia puramente destructiva, desligada, si se quiere, de una productividad que no sea la de la guerra. El melancólico, sin más armas que su carne, pone en cuestión verdades y sistemas, haciendo gala del arrojo individualista de un héroe de tragedia. Con el suicidio dispone de su propia vida negándole tal potestad a los dioses: recuérdese el ejemplo de Ajax, que primero rechaza su ayuda y luego su piedad, dándose muerte (36). Y negándole tal poder, también, a la biología, que a duras penas puede explicar la abolición de los instintos de que hace gala. Abandonándose a la acedía, puso también en guardia el orden conventual del ora et labora. Quizá por esa tendencia al hastío, al hartazgo, proclamó Picabia con sutileza dadá que «el más bello de los descubrimientos del hombre es el bicarbonato sódico» (31). Finalmente, aunque no sirva ni de lejos para agotar estas reflexiones, el melancólico resulta, en esta sociedad en que se multiplican los objetos de consumo, radicalmente insobornable. A la deriva de la inhibición y la inapetencia, incapaz de disfrutar, ni produce ni consume. Y ello tanto en su versión triste, en la que parece no poder tentársele con nada, como en su versión maníaca, cuya excitación sin sentido y cuya voracidad ilógica recuerdan de lejos a las propuestas estético-políticas de la Internacional Situacionista (18).

\section{La propuesta paranoica}

A punto de otorgar al melancólico el reinado en el arte y en la subversión, surge ante nosotros el escollo de la locura más inquietante, la que se nos presenta más radicalmente extraña y nos inspira un miedo más cerval. Aquélla que a partir de las ruinas del lenguaje construye uno propio con ambición de perfección, y cuyas aceradas aristas ponen de continuo en entredicho nuestras precarias seguridades. Hablamos de la paranoia.

Dibujamos durante páginas una melancolía inútil que luego se reveló como una potencia creativa sin par. Sucede, sin embargo, que empezamos a contemplar ahora su arte como «demasiado humano». Igual que el vino, la atrabilis puede hacer de un hombre todos los hombres, las infinitas versiones de lo humano, que no es poco, pero no puede curarlo de su humanidad. Su creación es mera combinatoria, pero su raíz es la misma herida con que luchamos todos. Tiene ante sí la cadena de un lenguaje que se ha detenido con el deseo. Puede torcerla, estudiarla, glosarla, como un Burton. Puede incluso sorprendernos. Pero será una sorpresa porque es sólo atávicamente familiar. El melancólico no ha dejado 
de hablar nuestra misma lengua, aunque lo haga con especial soltura. La creación demiúrgica, la que surge de la nada, la verdaderamente original, debemos concedérsela al loco más genuino, a aquél que consagra su vida al delirio y que enfrenta la titánica tarea de construir todo un mundo a partir de los derrelictos de un lenguaje naufragado.

Igual nos ocurre con la capacidad subversiva que atribuimos a la melancolía. Se ha dicho que, junto con la histeria y la paranoia, forma la terna de escollos principales con que ha tropezado la nosografía. No parecía descabellado atribuirles también, como actitudes ante la vida antes que como enfermedades mentales, una cierta medida de rebeldía frente a los excesos del poder, psiquiátrico u otro. En el caso de la histeria, tal rebeldía venía sugerida por su afán en señalar la falta en el otro, y por su insatisfacción esencial. Ocurre que entendimos la multiplicación de los objetos de consumo como una trampa en la que su voraz deseo tendería a caer sin remedio, y volvimos la mirada a la melancolía. Pero nuestro propio razonamiento vino a cortarnos el paso. Auténticamente revolucionario sería el melancólico que persevera en su posición y se mata. $\mathrm{O}$ el que, dándose ya por muerto, se abandona. El que no apetece y basta. Pero el melancólico se ha levantado en armas contra su propia soledad y, aunque dramática, su lucha es por la recuperación del vínculo perdido. Lucha en la que, como vimos, se deja seducir por las más diversas salidas y renuncia las más de las veces a la muerte en favor de una vida parecida a del neurótico, a la del engañado guiado por la mala fe. Algo que no le ocurre al paranoico, que, en su cara a cara con un otro por entero de su invención, resulta mucho más exigente. Deberíamos quizá esperar de él la labor de zapa que socave los cimientos de nuestras certezas. Su rigor implacable, que no nace de la humanidad sino del desierto que la precede, podría acaso ayudarnos a desvelar razones inadvertidas para nosotros. Denunciante y sospechoso, leninista, utilizaría nuestro propio lenguaje para mostrarnos sus insuficiencias y engaños.

\section{Final}

Como prometíamos al principio, hablamos de un final por no atrevernos a hallar en las páginas precedentes una conclusión. Rindámonos. Como en el experimento de Schrödinger, tenemos ante nosotros, tras una densa oscuridad, dos gatos. O aun miles: uno muerto, otro herido, otros aburridos o asustados. Tras muchos meandros, debemos reconocer que, o bien el trabajo melancólico es inútil y conduce de forma genuina al suicidio, o bien es la tierra yerma de donde nacen las mieses de la creación más fecunda y de la posibilidad más dolorosa- 
mente humana de vivir. O bien ambas opciones a la vez, o todo lo contrario, y el triunfo es la muerte y la vida, como el arte y la melancolía, es una pasión inútil que a duras penas logra sacarnos del absurdo.

Hable Cioran, de nuevo: «Porque no reposa sobre nada, porque carece hasta de la sombra misma de un argumento, es por lo que perseveramos en la vida. La muerte es demasiado exacta; todas las razones se encuentran de su lado» (10).

\section{BIBLIOGRAFÍA}

(1) AвRAHAM, K., «Notas sobre la investigación y tratamiento psicoanalíticos de la locura maníaco-depresiva y condiciones asociadas» y «Un breve estudio de la evolución de la libido, considerada a la luz de los trastornos mentales», en Obras escogidas, Barcelona, RBA, 2006, pp. 118132 y 333-395.

(2) Álvarez, J. M., Estudios sobre la psicosis, Vigo, AGSM, 2006.

(3) Álvarez, J. M., La invención de las enfermedades mentales, Madrid, DOR, 1999.

(4) American Psychiatric Association, DSM-IV, Barcelona, Masson, 1995.

(5) ARISTÓteles, El hombre de genio y la melancolía, Barcelona, Quaderns Crema, 1996.

(6) Baudelaire, C., Las flores del mal, Madrid, Cátedra, 2006.

(7) Baudelaire, C., Pequeños poemas en prosa, Barcelona, Fontana, 1995, p. 21.

(8) Bolaños, M., Pasajes de la melancolía, Valladolid, Junta de Castilla y León, 1996.

(9) Borges, J. L., «La duración del Infierno», en Discusión, Madrid, Alianza, 1983, p. 87.

(10) Cioran, E. M., Adiós a la filosofía y otros textos, Madrid, Alianza, 1998, p.17.

(11) Cioran, E. M., Silogismos de la amargura, Barcelona, Tusquets, 2002, pp. 51 y 57.

(12) Colina, F., «Tristitia» y «Tristeza voluntaria e involuntaria», en Escritos psicóticos, Madrid, DOR, 1996, pp. 96-158.

(13) Colina, F., Deseo sobre deseo, Valladolid, Cuatro, 2006.

(14) Cotard, J., Études sur les maladies cérébrales et mentales, París, J.B. Baillière, 1891.

(15) Deleuze, G., Nietzsche, Madrid, Arena, 2000.

(16) Esquirol, E., Sobre las pasiones, Madrid, AEN, 2000. 8. ${ }^{\mathrm{a}}$ ed.

(17) Ey, H.; Bernard, P.; Brisset, Ch., Tratado de psiquiatría, Barcelona, Masson, 1978,

(18) FERrer, C., «Prólogo», en DÉBORD, G. La sociedad del espectáculo, Buenos Aires, La Marca, 1995.

(19) Foucault, M., Historia de la locura en la época clásica, México DF, Fondo de Cultura Económica, 1976.

(20) FreUd, S., «Duelo y melancolía», en Obras completas, Madrid, Biblioteca Nueva, 1973, pp. 2.091-2.100.

(21) Freud, S., «Manuscrito G», en Obras completas, Buenos Aires, Amorrortu, 1976, p. 244.

(22) FREUd, S., op. cit., p. 240.

(23) Huertas, R., El siglo de la clínica, Madrid, Frenia, 2004.

(24) Jaspers, K., Psicopatología General, Buenos Aires, Beta, 1975.

(25) KleIN, M., «Contribución a la psicogénesis de los estados maníaco-depresivos» y «El duelo y su relación con los estados maníaco-depresivos», en Obras completas I, Barcelona, RBA, 2006, pp. 279-307 y 351-383. 
(26) Kraepelin, E., Lehrbuch der Psychiatrie 8. ${ }^{a}$ ed. Leipzig, Barth, 1909-1913, Buenos Aires, Polemos, 1996.

(27) Lacan, J., Seminario 8, Buenos Aires, Paidós, 2003.

(28) LANTÉRI-Laura, G., Ensayo sobre los paradigmas de la psiquiatría moderna, Madrid, Triacastela, 2000.

(29) LANTÉRI-LAURA, G., La sémiologie psychiatrique; Histoire et structure, en Fuentenebro, F.; Huertas, R.; Valiente, C. (eds.), Historia de la psiquiatría en Europa. Temas y tendencias, Madrid, Frenia, 2003.

(30) Minkowski, E., El tiempo vivido, México DF, Fondo de Cultura Económica, 1973.

(31) Picabia, F., «391 n. . 13», en Hugnet, G., La aventura dadá, Madrid, Júcar, 1973, p. 244.

(32) Pigeaud, J., «Introducción», en ARISTÓTEles, El hombre de genio y la melancolía, Barcelona, Quaderns Crema, 1996.

(33) PInel, Ph., Tratado médico-filosófico de la enagenación del alma o manía, Madrid, Imprenta Real, 1804 (ed. facsímil).

(34) Roudinesco, E.; Plon, M., Diccionario de psicoanálisis, Buenos Aires, Paidós, 1998.

(35) SÉGLAS, J., Leçons cliniques sur les maladies mentales et nerveuses, París, Asselin et Houzeau, 1895.

(36) SóFOCLES, «Áyax», en Tragedias, Madrid, Edaf, 1985, pp. 29-78.

(37) StARobinski, J., «Habla Demócrito» (prefacio), en BURTON, R., Anatomía de la melancolía, Madrid, AEN, 2003.

(38) Tellenbach, H., La melancolía, Madrid, Morata, 1976.

* Francisco Ferrández Méndez, M.I.R. II de Psiquiatría. Hospital Psiquiátrico «Dr. Villacián». Valladolid. Correspondencia. Francisco Ferrández Méndez, Centro Asistencial «Dr. Villacián», C/ Orión, 2. 47014 Valladolid. fferrandez@ hotmail.com

** Fecha de recepción: 22-XI-2006. 